\title{
Hypophosphatemia after right hepatectomy for living donor liver transplantation
}

\author{
Kelly W Burak $M D^{1}$, Charles B Rosen $M D^{1}$, Jeff L Fidler $M D^{2}$, Gina $K$ Hesley $M D^{2}$, \\ David Nagorney MD¹, Michael R Charlton MD ${ }^{1}$, David J Brandhagen MD ${ }^{1}$
}

\begin{abstract}
KW Burak, CB Rosen, JL Fidler, et al. Hypophosphatemia after right hepatectomy for living donor liver transplantation. Can J Gastroenterol 2004;18(12):729-733.
\end{abstract}

\begin{abstract}
Hypophosphatemia has been described in patients undergoing right hepatectomy for liver cancer and in living donors for liver transplantation who also received total parenteral nutrition. At the study centre, significant hypophosphatemia $(0.36 \mathrm{mmol} / \mathrm{L}$ or less $)$ requiring intravenous replacement was seen in two of the first nine living donors for adult-to-adult liver transplantation. To determine the frequency of hypophosphatemia in living donors, the authors obtained phosphate levels on stored serum samples from postoperative days 0 , 1,3 and 7 in all nine patients, none of whom were on total parenteral nutrition. Within the first week, hypophosphatemia developed in $55.6 \%$ of patients and phosphate levels returned to normal by day 7 in all nine patients. One patient had normal phosphate levels during the first week, but had profound hypophosphatemia $(0.32 \mathrm{mmol} / \mathrm{L})$ on day 14 when he presented with a Staphylococcus aureus infection of a bile collection and significant hypoxemia. The extent of hepatectomy and the rate of liver regeneration, estimated by baseline and postoperative day 7 volumetric computed tomography scans, did not correlate with the development of hypophosphatemia. In conclusion, hypophosphatemia is common in living donors undergoing right hepatectomy and may be associated with complications. All living donors should be monitored for the development of hypophosphatemia during the first two postoperative weeks.
\end{abstract}

Key Words: Hepatectomy; Hypophosphatemia; Liver transplantation; Surgical complications

\section{L'hypophosphatémie après une hépatectomie droite pour une greffe hépatique par donneur vivant}

L'hypophosphatémie est décrite chez les patients subissant une hépatectomie droite secondaire à un cancer hépatique et chez des donneurs vivants en vue d'une transplantation hépatique qui ont également reçu une alimentation parentérale totale. Au centre d'étude, une hypophosphatémie marquée $(0,36 \mathrm{mmol} / \mathrm{L}$ ou moins) exigeant une restauration intraveineuse a été observée chez deux des neuf premiers donneurs vivants d'une transplantation hépatique d'adulte à adulte. Pour déterminer la fréquence d'hypophosphatémie chez les donneurs vivants, les auteurs ont obtenu les taux de phosphate d'échantillons sériques mis en réserve les jours postopératoires $0,1,3$ et 7 chez les neuf patients, dont aucun n'était sous alimentation parentérale totale. Au cours de la première semaine, une hypophosphatémie s'est développée chez 55,6 \% des patients, et le jour 7, les taux de phosphate étaient revenus à la normale chez les neuf patients. Un patient présentait des taux de phosphate normaux au cours de la première semaine, mais souffrait d'une hypophosphatémie profonde $(0,32 \mathrm{mmol} / \mathrm{L})$ le jour 14 , lorsqu'il s'est présenté avec une collection de bile infectée et une grave hypoxémie. L'importance de l'hépatectomie et le rythme de la régénération hépatique, évalués d'après une tomodensitométrie volumétrique au début et le jour 7 après l'opération, n'étaient pas corrélés avec le développement de l'hypophosphatémie. Pour terminer, l'hypophosphatémie est courante chez les donneurs vivants subissant une hépatectomie droite, et elle peut s'associer à des complications. Tous les donneurs vivants devraient être surveillés en cas d'apparition d'hypophosphatémie pendant les deux semaines postopératoires.
$\mathrm{H}$ ypophosphatemia has been described in patients undergoing major hepatic resections for liver cancer and has been associated with postoperative complications in these patients (1). In this initial report, serum phosphate levels fell in all 44 patients who underwent right hepatectomy for malignant tumours. Profound hypophosphatemia (less than $0.32 \mathrm{mmol} / \mathrm{L}$ ) developed in eight patients and was significantly associated with the development of major postoperative complications including infections, cardiac arrhythmias, respiratory arrest and hepatic insufficiency (1). Because of the donor organ shortage, many liver transplant centres have now initiated living donor liver transplant programs (2,3). Pomposelli et al (4) reported the development of hypophosphatemia as a complication of adult-to-adult living donor liver transplantation. Of their first 18 donors, profound hypophosphatemia (less than $0.32 \mathrm{mmol} / \mathrm{L}$ ) developed in $70 \%$ and severe hypophosphatemia $(0.32 \mathrm{mmol} / \mathrm{L}$ to $0.48 \mathrm{mmol} / \mathrm{L}$ ) developed in $30 \%$. However, all donors were receiving total parenteral nutrition (TPN), which in itself is known to cause hypophosphatemia (5). In contrast, a recent report (6) of 95 right lobe donors found that hypophosphatemia was mild and was not associated with increased morbidity.

We began an adult-to-adult living donor liver transplantation program at our study institution in June 2000. Significant hypophosphatemia $(0.36 \mathrm{mmol} / \mathrm{L}$ or less $)$ was observed in two of nine living donors during the first year of our program. However, serum phosphate levels were not routinely tested in all donors. We therefore sought to determine the frequency and severity of hypophosphatemia in our liver donors by using

${ }^{1}$ Transplant Center and ${ }^{2}$ Department of Radiology, Mayo Clinic, Rochester, Minnesota, USA

Correspondence and reprints: Dr David J Brandhagen, Transplant Center, Mayo Clinic, 2001 st Street Southwest, Rochester, Minnesota 55905,

USA. Telephone 507-266-1580, fax 507-266-2810, e-mail brandhagen.david@mayo.edu

Received for publication July 2, 2004. Accepted September 9, 2004 
TABLE 1

Serum phosphate levels before (day 0 ) and during the first week following right hepatectomy in nine living liver donors

\begin{tabular}{|c|c|c|c|c|c|c|c|}
\hline \multirow[b]{2}{*}{ Donor } & \multicolumn{4}{|c|}{ Serum $\mathrm{PO}_{4}$ levels $(\mathrm{mmol} / \mathrm{L})$} & \multirow[b]{2}{*}{$\%$ decrease in $\mathrm{PO}_{4}$} & \multirow[b]{2}{*}{ Degree of hypophosphatemia* } & \multirow[b]{2}{*}{ Complications } \\
\hline & Day 0 & Day 1 & Day 3 & Day 7 & & & \\
\hline 1 & 1.10 & 0.61 & 0.68 & 1.00 & 44.2 & Moderate & Wound infection \\
\hline 2 & 0.94 & 1.13 & 0.45 & 1.00 & 51.7 & Severe & \\
\hline 4 & 0.87 & 0.90 & 0.87 & 1.26 & 0.0 & None & \\
\hline 5 & 1.26 & 1.00 & 0.74 & 1.23 & 41.0 & Moderate & Peptic ulcer \\
\hline 8 & 1.42 & 0.36 & 0.61 & 1.03 & 75.0 & Severe & Bile leak \\
\hline 9 & 1.10 & 1.16 & 0.87 & 1.07 & 20.6 & Profound ${ }^{\dagger}$ & Bile leak \\
\hline Mean \pm & $.13 \pm 0.06$ & $0.90 \pm 0.06$ & $0.68 \pm 0.06$ & $1.16 \pm 0.03$ & $38.9 \pm 7.7$ & & \\
\hline
\end{tabular}

*Hypophosphatemia is defined as normal (>0.81 mmol/L), moderate $(0.81 \mathrm{mmol} / \mathrm{L}$ to $0.52 \mathrm{mmol} / \mathrm{L})$, severe (0.48 $\mathrm{mmol} / \mathrm{L}$ to $0.32 \mathrm{mmol} / \mathrm{L})$ and profound (<0.32 mmol/L). ${ }^{\dagger}$ Case 9 developed profound hypophosphatemia $(0.32 \mathrm{mmol} / \mathrm{L})$ on postoperative day 14 when presenting with an infected bile collection but had normal phosphate levels during the first week

stored serum samples. Phosphate supplements and TPN were not routinely used in our donors and, thus, the impact of these confounding variables was removed.

The reason for the development of hypophosphatemia after liver resection is unknown but is thought to be due to flux of phosphate into the liver for energy metabolism associated with liver regeneration. To examine this hypothesis, we used volumetric computed tomography (CT) at baseline to estimate the extent of liver resection and, on postoperative day 7, to estimate degree of liver regeneration. We attempted to correlate the extent of hepatectomy and degree of liver regeneration with the change in serum phosphate levels within the first postoperative week.

\section{METHODS}

The authors examined the first nine living donors in this adult-toadult living donor liver transplantation program between June 2000 and July 2001. All donors were emotionally related to the recipients and all donors underwent an extensive medical, anatomical and psychosocial evaluation before surgery. All donors underwent right hepatectomy. Because serum phosphate levels were not routinely measured in all patients, stored serum samples from before the operation (day 0 ) and postoperative days 1,3 and 7 were used to determine serum phosphate levels. Serum inorganic phosphate levels were measured by phosphammonium molybdate absorbance on a Hitachi 747-200 instrument (Roche Diagnostics, USA).

Helical CT scans with three-dimensional volumetric renderings were used preoperatively to estimate donor graft weight and degree of hepatectomy. All CT scans were performed on a multidector helical scanner (LightSpeed, GE Medical Systems, USA). The three-dimensional volumes were calculated using a dedicated workstation (Vital Images, USA). Volumetric CT scans were repeated on postoperative day 7 to estimate the degree of liver regeneration. Estimated percentage liver regeneration was calculated by the following formula:

(Day 7 liver volume -

baseline residual volume following hepatectomy) $\times 100$

$$
\text { Day } 7 \text { liver volume }
$$

Data are expressed as mean \pm SEM. Correlation between liver resection, degree of liver regeneration and change in phosphate levels were calculated using Excel (Microsoft Corp, USA). Donors gave informed consent for liver donation and to have serum stored for research purposes. The Mayo Clinic Institutional Review Board approved the study.

\section{RESULTS}

Nine living donors underwent right hepatectomy (five female, four male). The mean age of the donors was $35.8 \pm 10.9$ years and their mean weight was $83.5 \pm 6.6 \mathrm{~kg}$. Hypophosphatemia was prospectively identified in two of our nine living donors (donors 8 and 9). Donor 8, a 49-year-old woman who donated to her husband, was noted to have hypophosphatemia on the second postoperative day $(0.36 \mathrm{mmol} / \mathrm{L})$. At the time, she was found to have bile in surgical drains and endoscopic retrograde cholangiopancreatography confirmed a small bile leak that was treated successfully with endoscopic stenting. Intravenous phosphate replacement was started and phosphate levels returned to normal within one day. Donor 9, a 47-year-old man who donated to his uncle, presented on postoperative day 14 with fever $\left(39.0^{\circ} \mathrm{C}\right)$ and was noted to be hypoxemic (oxygen saturation $80 \%$ on room air). A chest $\mathrm{x}$-ray demonstrated a small right pleural effusion and a spiral CT scan excluded a pulmonary embolus. A CT scan of the abdomen demonstrated a subphrenic collection consistent with an abscess, and a CT-guided percutaneous drainage was performed. He was found to have profound hypophosphatemia $(0.32 \mathrm{mmol} / \mathrm{L})$ and intravenous phosphate was started. Cultures from aspirated fluid and blood grew Staphylococcus aureus and he improved on parenteral antibiotics.

Donor serum phosphate levels from the first week following surgery were measured from stored serum samples and are shown in Table 1. Serum phosphate levels were normal (greater than $0.81 \mathrm{mmol} / \mathrm{L}$ ) in all donors before the operation (range $0.87 \mathrm{mmol} / \mathrm{L}$ to $1.42 \mathrm{mmol} / \mathrm{L}$ ). Phosphate levels fell by the third postoperative day in eight of nine donors. The mean decrease was $39 \%$ (range $0 \%$ to $75 \%$ ). Within the first week following surgery, hypophosphatemia developed in five of nine donors $(55.6 \%)$ and phosphate levels returned to normal in all donors by day 7 . Only one donor received replacement therapy within the first week (donor 8). As discussed above, donor 9 had normal phosphate levels during the first week but developed profound hypophosphatemia $(0.32 \mathrm{mmol} / \mathrm{L})$ on day 14 when he presented with an infected bile collection and $S$ aureus bacteremia. 
TABLE 2

Volumetric computed tomography (CT) scan results at baseline and seven days following right hepatectomy in nine living liver donors

\begin{tabular}{|c|c|c|c|c|c|}
\hline \multirow[b]{2}{*}{ Donor } & \multicolumn{3}{|c|}{ Baseline CT } & \multicolumn{2}{|c|}{ Day $7 \mathrm{CT}$} \\
\hline & $\begin{array}{l}\text { Estimated total } \\
\text { liver volume }(\mathrm{g})\end{array}$ & $\begin{array}{l}\text { Estimated right } \\
\text { graft volume (g) }\end{array}$ & $\begin{array}{l}\text { Percentage } \\
\text { hepatectomy }\end{array}$ & $\begin{array}{l}\text { Estimated liver } \\
\text { volume (g) }\end{array}$ & $\begin{array}{l}\text { Percentage } \\
\text { regeneration }\end{array}$ \\
\hline 1 & 1259 & 709 & 56.3 & 647 & 17.6 \\
\hline 3 & 1539 & 1129 & 73.4 & 961 & 134.4 \\
\hline 4 & 1444 & 829 & 57.4 & 905 & 47.2 \\
\hline 7 & 1301 & 829 & 63.7 & 761 & 61.2 \\
\hline 8 & 1466 & 1050 & 71.6 & 714 & 171.6 \\
\hline 9 & 1764 & 1167 & 66.2 & 1252 & 209.7 \\
\hline Mean \pm SEM & $1674 \pm 123$ & $1072 \pm 85$ & $63.8 \pm 1.9$ & $964 \pm 75$ & $86.3 \pm 21.4$ \\
\hline
\end{tabular}

*Percentage regeneration was calculated by subtracting the estimated liver volume on postoperative day 7 from the baseline residual volume of liver following hepatectomy, dividing by the estimated liver volume on postoperative day 7 and multiplying by 100

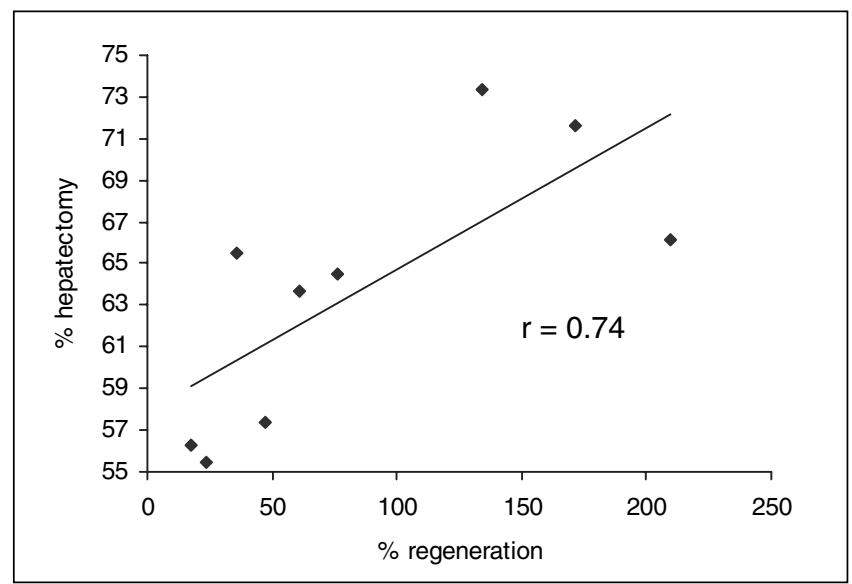

Figure 1) Percentage of hepatectomy (estimated by baseline volumetric computed tomography scan) was strongly correlated with percentage of liver regeneration (estimated by volumetric computed tomography scan on postoperative day 7) in nine living donors undergoing right hepatectomy

Complications were noted in six of the donors and are summarized in Table 1. Minor wound infections were noted in two donors. One donor developed a peptic ulcer that responded to therapy with a proton pump inhibitor. Three donors developed bile leaks, with one responding to endoscopic stenting and the other two requiring percutaneous drainage of bile collections.

The results of the volumetric CT scans are shown in Table 2. The estimated average hepatectomy was $63.8 \%$ (range $55.5 \%$ to $73.4 \%$ ). Residual left lobe hypertrophy was seen in all donors by day 7 with an average increase in volume of $86.3 \%$ (range $17.6 \%$ to $209.7 \%$ ). The percentage of hepatectomy strongly correlated with the degree of liver regeneration by day 7 , with a correlation coefficient of 0.74 (Figure 1 ). The decrease in serum phosphate levels correlated poorly with the extent of hepatectomy $(r=0.25)$ and the percentage of liver regeneration was not predictive of the percentage decrease in phosphate levels ( $r=-0.006$; Figure 2).

\section{DISCUSSION}

Hypophosphatemia occurred in two-thirds of our living donors after right hepatectomy. Within the first week following surgery,

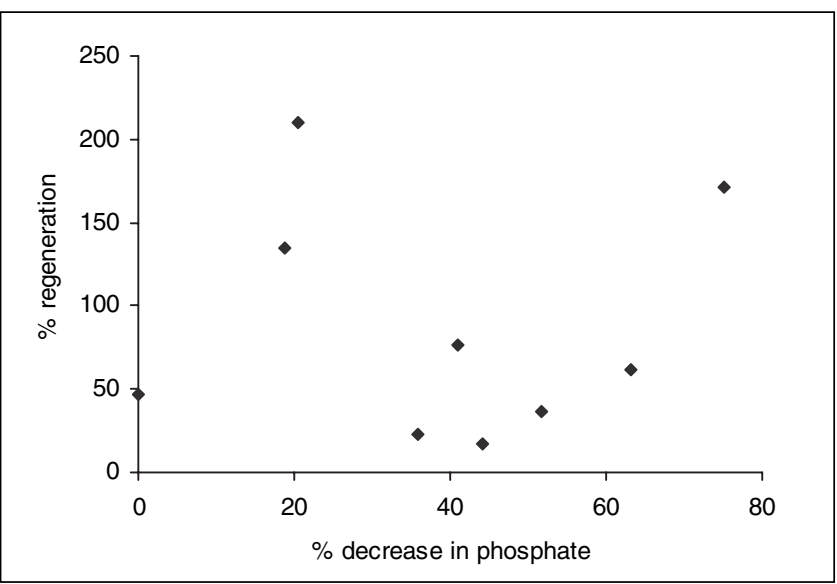

Figure 2) Percentage of liver regeneration by the seventh postoperative day (estimated using volumetric computed tomography scan) was not predictive of the percentage decrease in serum phosphate levels from baseline within the first week following right hepatectomy in nine living donors

five of nine donors (55.6\%) developed hypophosphatemia. The hypophosphatemia was moderate $(0.81 \mathrm{mmol} / \mathrm{L}$ to $0.52 \mathrm{mmol} / \mathrm{L})$ in two donors and severe $(0.48 \mathrm{mmol} / \mathrm{L}$ to $0.32 \mathrm{mmol} / \mathrm{L}$ ) in another three donors. One other donor developed hypophosphatemia two weeks after surgery but had normal phosphate levels during the first postoperative week.

Our results differ from two previously published studies. Pomposelli et al (4) reported that hypophosphatemia was universal in all 18 of their living donors following right hepatectomy. However, all donors in their series received TPN. TPN in itself has been reported to cause hypophosphatemia (5) and, therefore, TPN may have contributed to the hypophosphatemia in their living donors. Even when the last 12 donors in their series were given aggressive phosphate supplementation $(60 \mathrm{mmol} /$ day started on postoperative day 1 as part of their TPN), severe hypophosphatemia was still seen in $30 \%$ of donors and profound hypophosphatemia was seen in $8 \%$ (4). In contrast, a study by Tan et al (6) of 95 right lobe donors did not find hypophosphatemia to be a major problem. Most donors developed mild hypophosphatemia but profound hypophosphatemia (less than $0.32 \mathrm{mmol} / \mathrm{L}$ ) was not observed 
in any donors. Morbidity was not associated with hypophosphatemia when aggressive phosphorus replacement was initiated.

Contrary to the study by Pomposelli et al, we did not find hypophosphatemia to be 'universal' in our living donors. On the other hand, our results differ from Tan et al in that at least two of our patients developed serious complications potentially attributable to severe hypophosphatemia. None of the donors in our series were on TPN, thereby eliminating the potentially confounding effect of TPN present in the study by Pomposelli et al. There are a few potential limitations of our study including its retrospective nature and the fact that stored serum samples were only available on alternate postoperative days. In the study by Pomposelli et al, the nadir of phosphate levels was noted on the second postoperative day $(0.36 \pm 0.03 \mathrm{mmol} / \mathrm{L})$ (4). We may have missed hypophosphatemia that occurred on the second postoperative day and, thus, may have underestimated the prevalence of hypophosphatemia in our patients.

George and Shiu (1) were the first to identify the significance of hypophosphatemia after major hepatic resections in a series of cancer patients. They correlated profound hypophosphatemia with increased infectious, cardiac and respiratory postsurgical complications. In our small series, there were six postsurgical complications: two wound infections, one peptic ulcer and three bile leaks. Severe or profound hypophosphatemia was seen in two of the three donors with bile leaks. Overall, one-half of donors who developed severe or profound hypophosphatemia had a complication. However, two of the three patients who did not develop hypophosphatemia also had postoperative complications. Therefore, based on our small sample size, it is difficult to correlate the risk of complications with the presence of hypophosphatemia. We also cannot answer the question of whether it is the partial hepatectomy or the complication (bile leak and infection), or the combination of the two, that led to the hypophosphatemia.

Hypophosphatemia has been associated with infectious, cardiovascular, respiratory and neurological complications (7). Hypophosphatemia may increase the risk of sepsis by impairing leukocyte and macrophage function (8). Cardiovascular complications include arrhythmias (1) and myocardial suppression (9). Pomposelli et al (4) described a live liver donor, with no previous history of cardiac disease, who developed pulmonary edema during the phosphate nadir. Respiratory muscle dysfunction is a recognized complication of hypophosphatemia (10), and respiratory arrest has complicated hypophosphatemia following hepatic resection (1). Neurological complications include an altered level of consciousness, seizures, tremor and parasthesia, including a case of temporary radial neuropraxia in a live liver donor with associated hypophosphatemia (4).

Hepatic failure has been attributed to hypophosphatemia (11) and, in the series by George and Shiu (1), death due to hepatic failure was seen in one patient with profound hypophosphatemia.

Hypophosphatemia may lead to cell or organ dysfunction through several potential mechanisms (12). Severe hypophosphatemia diminishes levels of 2,3-diphosphoglycerate in erythrocytes, resulting in increased oxygen affinity for hemoglobin and subsequent tissue hypoxia. Serum phosphate levels less than $0.16 \mathrm{mmol} / \mathrm{L}$ are associated with impaired glycolysis. In addition, severe hypophosphatemia is associated with depletion of cellular ATP, the energy source for most cellular functions. Furthermore, inorganic phosphate is an independent regulator of cardial adenosine formation and thus, potentially, cardiac contractility. In skeletal muscle, hypophosphatemia is associated with impaired membrane functional and structural integrity.

Hypophosphatemia is most likely to occur during the first week following right hepatectomy. In our series, serum phosphate levels had returned to normal by day 7 in all donors. The other two reports found that serum phosphate levels returned to normal in all donors by day $5(4,6)$. Interestingly, one of our donors (donor 9) had normal serum phosphate levels during the first week after surgery but presented with profound hypophosphatemia two weeks following his liver resection. At that time, he had an infected bile collection and Staphylococcus septicemia. His significant hypoxemia (oxygen saturation $80 \%$ ) was likely a result of his profound hypophosphatemia ( $0.32 \mathrm{mmol} / \mathrm{L})$. Because hypophosphatemia decreases production of 2,3-diphosphoglycerate within erythrocytes, a shift in the oxygen saturation curve may result in hypoxemia and tissue hypoxia. In fact, in the series by George and Shiu (1), profound hypophosphatemia was the cause of respiratory arrest in one patient following liver resection. Our donor (donor 9) demonstrates that hypophosphatemia can be a relatively late development following liver resection, especially if there are associated complications. Because hypophosphatemia is thought to suppress immune function (1), one could argue that he was at increased risk for septicemia because of low serum phosphate levels. However, this donor had normal serum phosphate levels during the first week following surgery despite significant liver regeneration (estimated at $209.7 \%$ on his day 7 CT scan). It is more likely that the additional metabolic stress of septicemia, in the setting of rapid liver regeneration, resulted in the late development of profound hypophosphatemia in this donor.

The reasons for the development of hypophosphatemia following right hepatectomy are poorly understood. The proposed mechanism of hypophosphatemia is the movement of phosphorous into a rapidly regenerating liver for the protein synthesis and phosphorylation of nucleotides (ATP and guanosine triphosphate). In our series, an average of $86.3 \%$ liver regeneration was seen by the seventh day following surgery. Interestingly, the degree of hepatectomy estimated on the baseline CT scan was strongly correlated with the degree of regeneration noted after the first week $(r=0.74)$. In other words, the larger the hepatectomy, the faster the liver regeneration. However, there was only a weak correlation between the percentage hepatectomy and the percentage decrease in serum phosphate levels within the first week. Furthermore, the percentage of liver regeneration on day 7 was not correlated with the percentage decrease in serum phosphate levels. Therefore, reasons other than rapid liver regeneration may account for the development of hypophosphatemia in these donors.

Interestingly, hypophosphatemia was also seen in six of the nine recipients of the right hepatic allografts within the first week following liver transplantation. In the recipients, hypophosphatemia was moderate in five patients and severe in one patient. None of the liver transplantation recipients received TPN during this time period. Significant liver regeneration was also seen in the recipient allograft after one week $(29.8 \pm 4.7 \%)$, suggesting that liver regeneration may contribute to the hypophosphatemia in recipients of right liver allografts. 


\section{CONCLUSIONS}

Hypophosphatemia is very common but not universal in donors undergoing right hepatectomy for adult-to-adult liver transplantation. Hypophosphatemia may be associated with serious donor complications. Hypophosphatemia occurs most commonly during the first week following surgery. However, donors with later complications may also be at risk for hypophosphatemia. Although rapid liver regeneration is thought to be the cause of hypophosphatemia in these donors, we did not find a correlation between liver regeneration and a decrease in serum

\section{REFERENCES}

1. George R, Shiu MH. Hypophosphatemia after major hepatic resection. Surgery 1992;111:281-6.

2. Marcos A, Fisher RA, Ham JM, et al. Selection and outcome of living donors for adult to adult right lobe transplantation. Transplantation 2000;69:2410-5.

3. Pomfret EA, Pomposelli JJ, Lewis WD, et al. Living donor adult liver transplantation using right lobe grafts: Donor evaluation and surgical outcome. Arch Surg 2001;136:425-33.

4. Pomposelli JJ, Pomfret EA, Burns DL, et al. Life-threatening hypophosphatemia after right hepatic lobectomy for live donor adult liver transplantation. Liver Transpl 2001;7:637-42.

5. Thompson JS, Hodges RE. Preventing hypophosphatemia during total parenteral nutrition. J Parenter Enteral Nutr 1984;8:137-9.

6. Tan HP, Madeb R, Kovach SJ, et al. Hypophosphatemia after 95 right-lobe living-donor hepatectomies for liver transplantation is not a significant source of morbidity. Transplantation 2003;76:1085-8.

7. Subramanian R, Khardori R. Severe hypophosphatemia: Pathophysiologic implications, clinic presentations and treatment. Medicine (Baltimore) 2000;79:1-8. phosphate levels. All living donors should undergo monitoring for hypophosphatemia during their first postoperative week and the role of prophylactic supplementation of phosphorous in these patients deserves further study. Serum phosphorous levels should be checked in all donors with complications that occur within the first few weeks after donor hepatectomy.

ACKNOWLEDGEMENTS: Dr Kelly W Burak was supported by the American Association for the Study of Liver Disease/ Schering Advanced Hepatology Fellowship.

8. Craddock PR, Yawata V, VanSanten L, Gilberstadt S, Silvis S, Jacob HS. Acquired phagocytic dysfunction: A complication of the hypophosphatemia of parenteral hyperalimentation. N Engl J Med 1974:290:1403-7.

9. Zazzo JF, Troche G, Ruel P, Maintenant J. High incidence of hypophosphatemia in surgical intensive care patients: Efficacy of phosphorous therapy on myocardial function. Intensive Care Med 1995;21:826-31.

10. Gravelyn TR, Brophy N, Seigert C, Peters-Golden M. Hypophosphatemia-associated respiratory muscle weakness in a general inpatient population. Am J Med 1988;84:870-6.

11. Nanji AA, Anderson FH. Acute liver failure: A possible consequence of severe hypophosphatemia. J Clin Gastroenterol 1985;7:338-40.

12. Larsen VH, Waldau T, Gravesen H, Siggaard-Andersen O. Erythrocyte 2,3-diphosphoglycerate depletion associated with hypophosphatemia detected by routine arterial blood gas analysis. Scand J Clin Lab Invest Suppl 1996;224:83-7. 


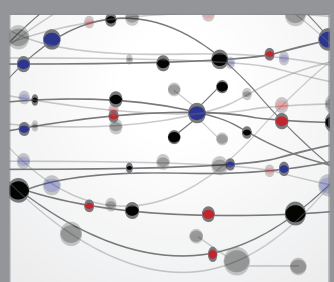

The Scientific World Journal
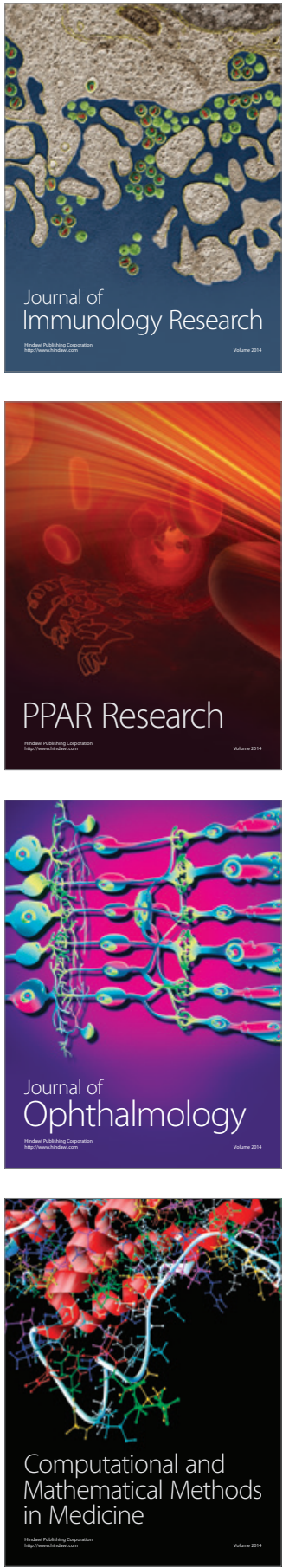

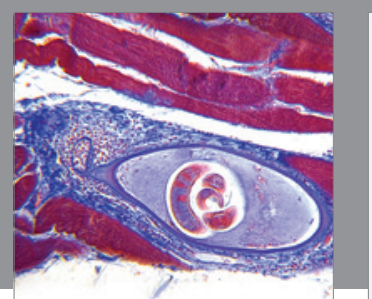

Gastroenterology Research and Practice

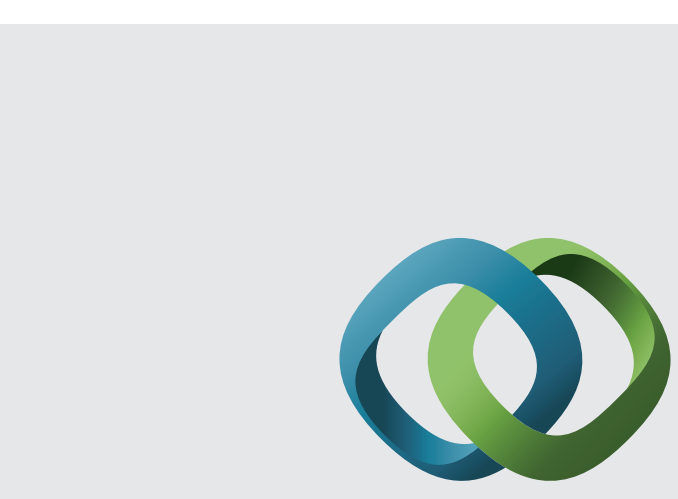

\section{Hindawi}

Submit your manuscripts at

http://www.hindawi.com
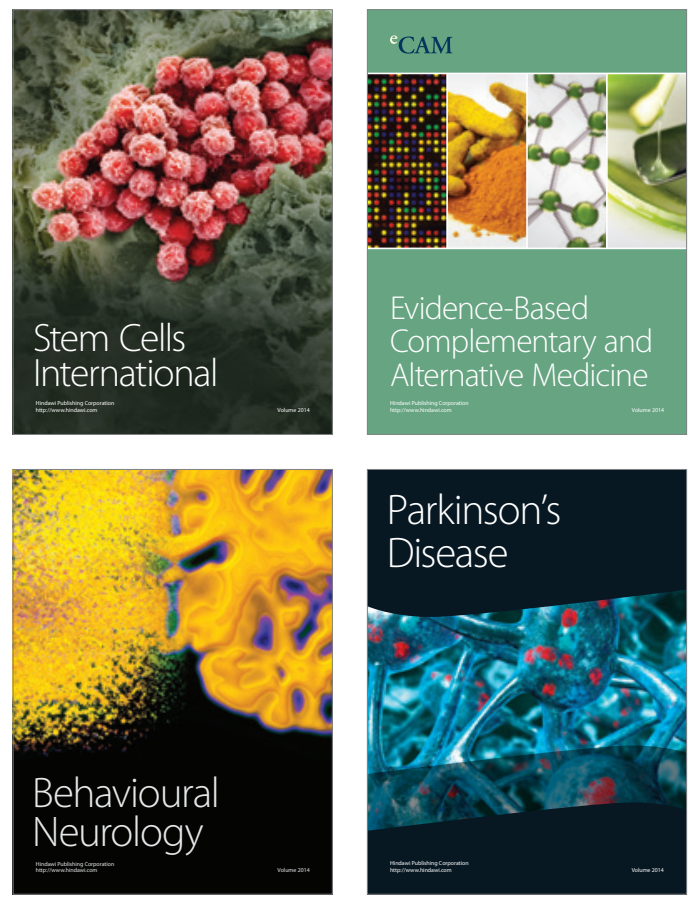
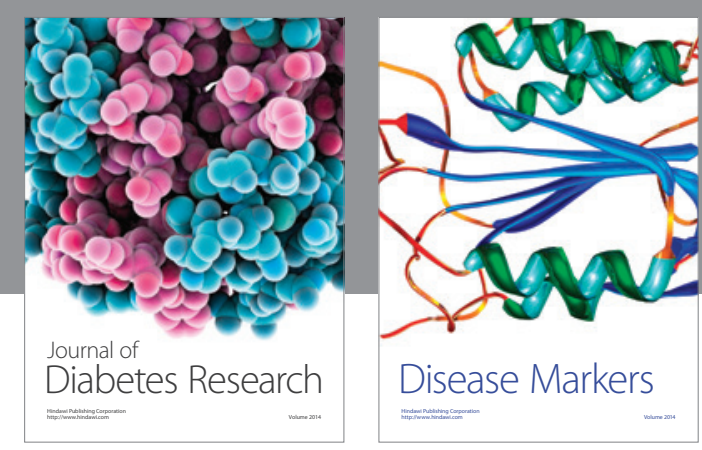

Disease Markers
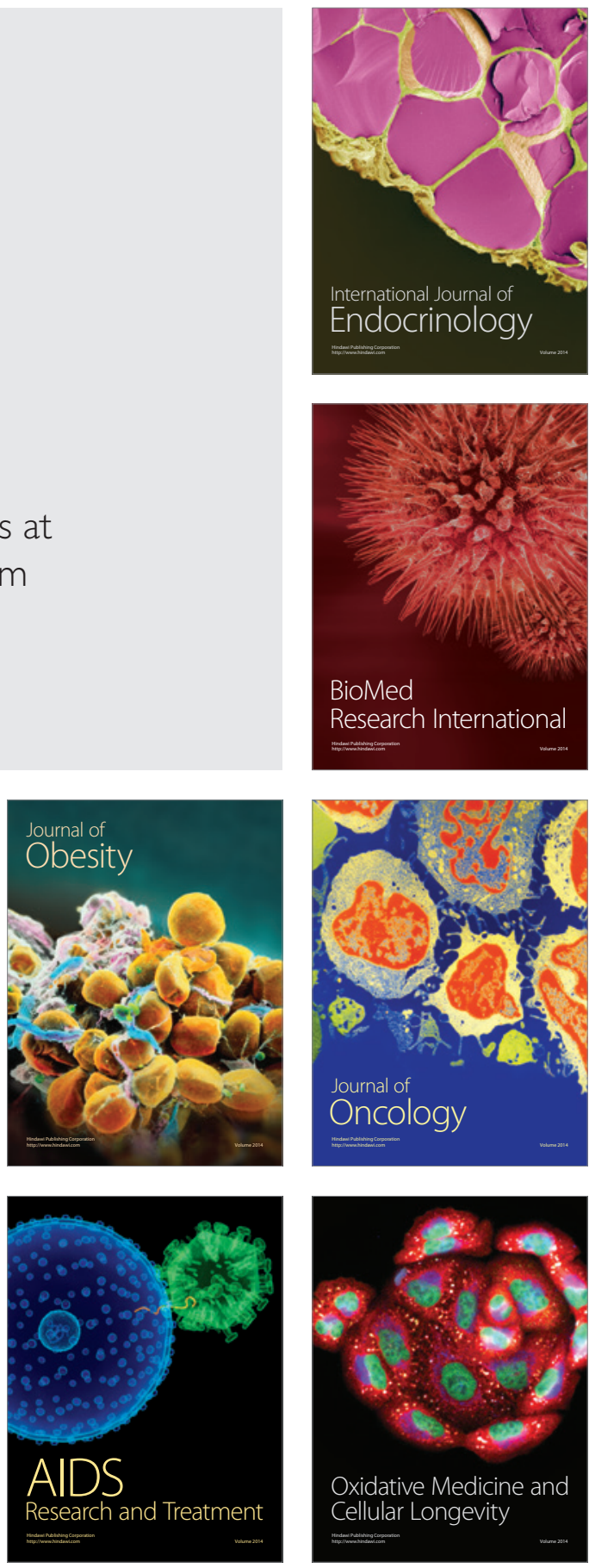